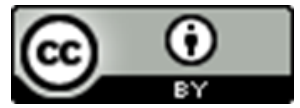

\title{
O SENTIDO DA FESTA: OLHAR RETROSPECTIVO SOBRE O CICLO DO VERÃO BAIANO VINTE ANOS DEPOIS
}

\author{
Edson Dias Ferreira ${ }^{1}$
}

\begin{abstract}
Resumo: O texto aqui apresentado lança um olhar para festa baiana vinte anos depois de ter iniciado a pesquisa. Os dados trazidos remontam àquele período, até porque ali eles foram coletados. A intenção é lidar com o ciclo festivo para mostrar que passado esse tempo os elementos que nutriam e nutrem o seu movimento não mudaram a tradição se mantém. Se por um lado há um chamamento à tradição, por outro há o reconhecimento de sua dinamicidade quando se observa a mudança de tempo, mudança de alguma ordem nos espaços onde elas se desenvolvem, além de saber que muitos dos seus personagens mais marcantes já não mais estão lá. Quantas daquelas mulheres ainda participam ativamente de cada uma das manifestações ensejadas pelo ciclo? Mas suas herdeiras, aquelas cujos ensinamentos foram apropriados seguem o movimento da festa e emprestam a ela suas motivações para continuarem participando. Assim ao revisitar a pesquisa que originou o texto foi possível olhar para festa vinte anos depois com os olhos de quem, em última instância, esteve lá e a viu passar. Nesse movimento, reacende o desejo de compará-la com o que se tem hoje.
\end{abstract}

Palavras chave: Ciclo de festas, Cultura popular, memoria, Bahia

\section{THE SENSE OF THE FESTIVITIES: A RETROSPECTIVE LOOK AT THE SUMMER CYCLE IN BAHIA, TWENTY YEARS LATER}

\begin{abstract}
The text presented here takes a retrospective look at the festivities in Bahia, twenty years after starting the research. The data have been traced back to that period, not least because they were collected then. The intention is to deal with the festive cycle to show that after that time the elements that have nourished its movement have not changed, the tradition remains. If, on the one hand, there is a call back to tradition, on the other, there is recognition of its dynamics even as time goes by and the spaces where they take place change with it, even if many of their major characters are no longer there. How many of those women still actively participate in each one of the events brought about by the cycle? Very few. But her heirs, those who have taken over their legacy, carry the movement of the festivities on and celebrate them at each cycle. Thus,
\end{abstract}

\footnotetext{
${ }^{1}$ Professor Pleno da Universidade Estadual de Feira de Santana - UEFS; Vice Coordenador do Programa de Pós-Graduação em Desenho, Cultura e Interatividade. Doutor em Ciências Sociais - Antropologia pela PUC-SP com Pós-Doutorado na mesma área e Instituição; fone: 75 - 31618865 e 71-999110918; endereço: Av. Transnordestina S/N, Novo Horizonte, Campus Universitário, DLA, Módulo 2, Feira de Santana - Ba, CEP: 44.036.900; E-mail: edson.orientacaomestrado@yahoo.com.br ; ORCID: https://orcid.org/0000-0003-4188-6736
} 
when revisiting the research that originated the text, it was possible to look at the party twenty years later with the eyes of someone who indeed was there and saw it go by. Its movement rekindles the desire to juxtapose it with what we have today.

Keywords: festivities cycle, popular culture, memory, Bahia

\section{EL SENTIDO DE LA FIESTA: UNA MIRADA RETROSPECTIVA AL CICLO DEL VERANO BAIANO HACE VEINTE AÑOS}

Resumen: El texto que se presenta echa un vistazo hacia la fiesta baiana después de empezada la investigación hace veinte años. Los datos que trajimos lleva a aquel periodo, hasta porque allí ellos fueron recopilados. La intención es lidiar con el ciclo festivo para mostrar que después de ese tiempo, los elementos que alimentaron y nutren su movimiento no han cambiado, y la tradición se mantienen. Si por un lado hay un llamado a la tradición, por otro se reconoce su dinamismo cuando se observa el cambio del tiempo, o el cambio de algún orden en los espacios donde las fiestas se han desarrollado, además de saber que muchos de sus personajes más llamativos ya no están allá. ¿ Cuántas de aquellas mujeres todavia participan activamente en cada uno de los eventos provocados por el ciclo? Pocas! Pero sus herederas, aquellas cuyas enseñanzas fueron apropiadas siguen el movimiento de la fiesta y le prestan sus motivaciones para continuar participando. Entonces, al volver a visitar la investigación que originó el texto fue posible mirar a la fiesta veinte años después con ojos de quien, en última instancia, estuvo allá y la vió pasar. En ese movimiento, se vuelve a encender el deseo de compararla con lo que se tiene hoy.

Palabras-clave: Ciclo de fiestas, cultura popular, memoria, Bahia.

\section{LE SENS DES FESTIVITÉS: UN REGARD RÉTROSPECTIF SUR LE CYCLE D'ÉTÉ À BAHIA, VINGT ANS PLUS TARD}

Résumé: Le texte présenté ici jette un regard rétrospectif sur les festivités de Bahia, vingt ans après le début de la recherche. Les données remontent à cette période, notamment parce qu'elles ont été collectées à l'époque. L'intention est de traiter le cycle festif pour montrer qu'après cette période les éléments qui ont nourri son mouvement n'ont pas changé, la tradition demeure. Si, d'une part, il y a un rappel à la tradition, d'autre part, il y a une reconnaissance de sa dynamique même au fil du temps et les espaces où ils se déroulent changent avec elle, même si beaucoup de leurs personnages principaux ne sont pas plus là-bas. Combien de ces femmes participent encore activement à chacun des événements provoqués par le cycle? Très peu. Mais ses héritiers, ceux qui ont repris leur héritage, portent le mouvement des festivités et les célèbrent à chaque cycle. Ainsi, en revisitant les recherches à l'origine du texte, il a été possible de regarder la fête vingt ans plus tard avec les yeux de quelqu'un qui était effectivement là et qui l'a vu passer. Son mouvement ravive le désir de le juxtaposer à ce que nous avons aujourd'hui.

Mots-clés: cycle des festivités, culture populaire, mémoire, Bahia 
No ano dois mil dei inicio a uma pesquisa que tinha por propósito dar conta de estudar a influencia da cultura negra no ciclo de festas populares da Bahia, cuja dinâmica se dá no período do verão entre os meses de dezembro e março. Começava, então, a execução do projeto aceito para o doutorado em Ciências Sociais pela Pontifícia Universidade Católica de São Paulo naquele ano.

Durante quatro anos acompanhei as festividades que compunham o ciclo, como resultado nasceu a tese Fé e festa nos janeiros da cidade da Bahia: São Salvador. Em consequência da pesquisa muitos outros desafios vieram, tendo como pano de fundo provocações resultantes da temática por ela abordada.

Para situar algumas das ações e produções inspiradas no seu produto procurei revisitar parte do caminho construído ao longo desses vinte anos. No âmbito profissional propus e/ou me integrei a projetos que resultaram em grandes desafios: A criação do Mestrado em Desenho, Cultura e Interatividade, na UEFS - Universidade Estadual de Feira de Santana - Ba, em 2005; a criação do Grupo de pesquisa Linguagens Visuais, Memória e Cultura na mesma Universidade; orientação de trabalhos com viés antropológico focado nas imagens, na cultura e na festa; vinculação ao Projeto ODEERE - Orgão de Educação e Relações Étnicas da UESB - Universidade Estadual do Sudoeste da Bahia como pesquisador colaborador. Este projeto, então coordenado pela Professora doutora Marise de Santana, iniciou como resultado da pesquisa de doutorado da mencionada professora, trazendo uma proposta de extensão com rápido amadurecimento no seu propósito, vindo alcançar a implantação da proposta de pós-graduação stricto sensu em Relações Étnicas e Contemporaneidade, dentro do qual participei ativamente de cada atividade.

Dessas incursões resultaram algumas das publicações que produzi sozinho e/ou em parceria nos últimos quinze anos. Dentre elas ao menos três estão diretamente vinculadas à tese produzida: Imaginário festivo e a cultura da fé na cidade do Salvador (2015), Imagens da cidade: fé e festa nos janeiros da cidade da Bahia (2017) e Festa baiana: religiosidade e consumo no ambiente festivo (2017)

Agora, não mais como pesquisador, mas como cidadão integrado à dinâmica da cidade, arguto observador, pude notar que as festas da minha infância, motivação maior para realização da pesquisa, mudaram com o tempo. A partir das considerações de BORNHEIM (1987) e MOURA (2004) foi possível assumir que a tradição somente subsiste porque é dinâmica, ela sempre está sujeita a inserção de elementos novos. Fruto 
das mudanças de tempo, espaço, relações e pessoas, a tradição se atualiza para continuar a cumprir o seu papel. Neste sentido, se o tempo é outro e o espaço passou por mudanças na sua constituição, se as pessoas são outras ou mudaram com o movimento do tempo, então a tradição ajustou-se a esse novo cenário e segue seu curso.

O recorte do trabalho envolve uma revisita ao período compreendido entre os anos de 2000 e 2004. Nesse intervalo de tempo foram observadas manifestações que se inserem em duas categorias a saber: festas com calendário fixo e festas com calendário móvel. Cabe mencionar que esta divisão ainda se mantem nos dias atuais.

As festas de calendário fixo registradas foram: a de Santa Bárbara, 4 de dezembro de 2003; de Nossa Senhora da Conceição da Praia, 8 de dezembro de 2002 e 2003; de Santa Luzia, dia 13 de dezembro de 2003; de Bom Jesus dos Navegantes, $1^{\circ}$ de janeiro e 31 de dezembro de $2001,1^{\circ}$ de janeiro de $2002,1^{\circ}$ de janeiro de 2003 e $1^{\circ}$ de janeiro de 2004; e de Iemanjá, 2 de fevereiro de 2002 e 2003.

Já aquelas com calendário móvel, registradas, foram a do Senhor do Bonfim, nos dias 11 de janeiro de 2001 - segunda quinta-feira do mês -, 17 de janeiro de 2002 terceira quinta-feira do mês -, 16 de janeiro de 2003 - terceira quinta-feira do mês - e 15 de janeiro de 2004 - terceira quinta-feira do mês. Em relação à Festa do Bonfim, o dia correspondente à sua realização se dá em função da marcação do segundo domingo após a Epifania, que corresponde ao dia da Festa de Reis. Foram realizados registros, ainda, da Festa de São Lázaro, dia 28 de janeiro de 2001, dias 26 e 27 de janeiro de 2002 e dia 26 de janeiro de 2003, sempre no último fim de semana do mês; da festa de Nossa Senhora da Conceição de Itapuã, no dia 8 de fevereiro de 2001, no dia 24 de janeiro de 2002, no dia 20 de fevereiro de 2003 e no dia 12 de fevereiro de 2004; e a última festa do calendário, o carnaval nos dias 24 de fevereiro de 2001, 9 e 10 de fevereiro de 2002, $1^{\circ}$ e 4 de março de 2003 e 23 de fevereiro de 2004.

$\mathrm{O}$ fato de ter acompanhado cada uma das manifestações do ciclo de festas aqui descritas possibilitou-me perceber o movimento expresso em cada uma dessas manifestações festivas. Estar lá significou poder ver além do visível que cada uma das manifestações mostra, por exemplo: um olhar, uma atitude particular no meio da multidão, o cheiro de que se reveste o ambiente, etc. Um dos muitos cheiros presentes nas festas de largo durante todo o ciclo, até o início da década de oitenta, era o cheiro da batida de pitanga, referida por Pierre Verger como "sangue baiano" - vermelho é a cor da pitanga - e seu cheiro tanto da folha quanto do fruto são inconfundíveis tendo algo 
de sedutor. Entretanto, hoje, desapareceu quase que por completo da festa, e outros cheiros foram incorporados e, certamente, no futuro não muito distante também serão lembrados ou simplesmente, no movimento da festa serão esquecidos, pois o presente não os chamou e o aflorar das lembranças depende do grau de importância de que se revestem no presente.

Em relação ao cenário festivo que Salvador apresenta, o turista constitui uma realidade à parte. Este elemento que progressivamente se insere no contexto dessas festividades dá às festas um outro tipo de movimento. Traços diferenciados se integram às manifestações, pois eles procedem de muitos lugares. Há aqueles que saem das cidades do interior do Estado, de outras partes do Brasil ou até de outros países. Isto implica uma diversidade muito grande dos motivos que os levam para a cidade. São motivos de caráter religioso, curiosidade, entretenimento e lazer. De modo geral, grande parte dos que visitam Salvador nesta época participa das manifestações.

É possível observar em parte da população de Salvador duas características bem definidas com as questões da cultura local: a reverência e o desconhecimento. Observase que, nesse contingente populacional, se encontra um número expressivo de jovens afro-brasileiros cuja atitude oscila entre a reverência ao fato de 'ser africano idealizado' e o total desconhecimento da influência africana presente em boa parte das ações que envolvem as festas populares que ocorrem na cidade.

A reverência vem em função da identificação com agremiações carnavalescas com forte apelo às tradições afro-brasileiras, os chamados 'blocos afros'. Este fato tem contribuído também para que eles tomem consciência de outras tantas manifestações como a religiosidade ancestral afro-brasileira. Nos últimos anos, as temáticas adotadas para as festas têm dado visibilidade aos blocos com esta característica. Tal fato também se verifica na música tocada nestas festividades - em 2004, pelo menos três das composições mais tocadas nos blocos animados por trio elétrico, durante o carnaval, traziam trechos ou refrãos inspirados em cânticos de candomblé que saúdam os orixás. Estes cânticos parecem fazer parte da memória coletiva da população baiana. Tanto é que as pessoas que participam da festa movimentam seus corpos inconscientemente, é o que se chamaria de memória involuntária proustiana. As sensações que os sons das músicas evocam trazem para o presente lembranças do passado, envolvendo todo o corpo e mente dos baianos que participam da festa. 
O carnaval $2004^{2}$ evocou a presença das várias etnias que contribuíram para a formação da cultura baiana; parece que ficou patente o caráter mestiço como peculiaridade do povo brasileiro em geral e do baiano em particular. Tal característica viu-se evidenciada desde a particularidade da festa carnavalesca ao próprio dia-a-dia do povo. Diria mesmo que, neste momento, cede, ainda que momentaneamente, o ímpeto da defesa de certas particularidades inerentes a cada grupo. Isto, de certa maneira, corresponde a um afrouxamento da fronteira étnica para salientar a ação coletiva que contribuiu para a formação da cultura baiana. Estimula-se, exatamente, a concentração nos aspectos que denotam a mistura, a miscigenação do povo, por isso mesmo a sua particularidade. Este fato revelou-se com alguma diferenciação em carnavais de anos anteriores, por exemplo os realizados nos anos de 2003, 2002 e 2001, respectivamente, com os temas: A Baiana, Carnaváfrica e Tieta, este último em homenagem a Jorge Amado.

As fotografias realizadas durante as festividades mostram algumas dessas passagens nas quais a cidade é destacada. É notório que a contribuição das culturas africanas às manifestações festivas da Cidade do Salvador foi e é de extrema importância. Ontem como hoje, depois das influências sofridas, as várias manifestações da cultura local têm nesse segmento uma das mais fortes fontes de inspiração e de reserva para novos empreendimentos. Tem sido a fonte dentro da qual a mídia tem bebido para a produção de bens de consumo. Ela, trata, estiliza, divulga e projeta na sua produção elementos da criatividade e da originalidade afro-brasileiras, recriando-os a partir de tais referências. Exemplo disso são os abadás - trajes assumidos pelos blocos carnavalescos já há algum tempo como indumentária para a festa -, as músicas cujas letras e o próprio movimento rítmico incluem, em todos os anos, elementos afrobrasileiros, e a dança, quase sempre reproduzindo movimentos do candomblé.

Assim, se a cultura afro-brasileira está na festa, o afro-descendente reivindica a sua participação. Da mesma maneira, esse discurso tem espaço e é apropriado muito frequentemente entre as pessoas que lidam com a questão da promoção cultural. Em depoimento a um jornal da cidade no ano de 2004, a então presidente da Bahiatursa, Eliana Dumet, assim define o sentimento do turista em relação às manifestações festivas da Bahia:

\footnotetext{
${ }^{2}$ Sob o tema 'Viva o povo brasileiro' em alusão ao livro de mesmo nome, o homenageado é João Ubaldo Ribeiro.
} 
O impacto de religiosidade no turista que chega a Salvador é muito forte. A capital baiana, que respira arte, música, cultura, tem um forte apelo de fé e espiritualidade em profusão de religiões, que misturam os católicos e os devotos do candomblé. Mesmo que o turista não acredite em nada, ele vai andando até o Bonfim emanando uma energia contagiante de fé nos milagres do santo. (SANTANA, 2004, p.1).

Essa reportagem sobre a Lavagem do Bonfim é reforçada por dois fatos registrados pelo mesmo jornal em dezembro de 2003 durante as comemorações de Santa Bárbara. Primeiro em um trecho da matéria, o jornal registra a opinião de um turista:

Lars Rijkaard, um holandês de 25 anos que mora na Argentina e está passando um mês em Salvador, demonstrava num portunhol a sua estupefação. "É muito bonito, pessoas católicas e de terreiro juntas, cantando para a santa e para o orixá, tudo na paz", dizia (BONFIM, 2003, p.4).

E, em seguida, o depoimento de uma freqüentadora regular da festa, Estelita Marinho, 66 anos, que relata com naturalidade. "Todo ano incorporo Iansã, aqui na praça mesmo" e continua a matéria: "[...], dizia, depois do transe presenciado por outras pessoas. 'Ainda estou zonza', frisou, enquanto apertava o terço para a reza de Santa Bárbara" (apud BONFIM, 2003, p.4).

O aspecto religioso evidenciado por Mattoso (1992), ao estudar a festa no século XIX, parece ainda encontrar eco no século XXI, pois a motivação religiosa alimenta e anima a manutenção da festa e, ainda hoje, aparece no discurso dos representantes do poder público. Entretanto, um diferencial se estabelece: no discurso atual, o aspecto religioso motiva parte dos freqüentadores, mas não determina a realização da festa, que se dá em função do interesse de tornar a cidade atraente e requisitada por quem a visita ou mesmo por potenciais visitantes, criando com isto divisas e impostos. Não apenas o poder público arrecada, mas também lucram os vários segmentos da economia, especialmente o turismo.

Ao referir-se à dinâmica da festa, Brandão (1989) chama a atenção para um aspecto interessante: as comunidades, em função do tamanho, atribuem diferentes graus de importância às festas pelo caráter que elas assumem. Segundo observa, nas cidades médias e grandes, as festas cívicas, históricas e profanas $-1^{\circ}$ de Janeiro, Carnaval, Dia do Trabalho, Sete de Setembro - assumem um grau maior de importância, enquanto nas pequenas cidades e nos povoados do interior essas mesmas festas ocupam um plano secundário e os festejos locais e religiosos - a festa do padroeiro, Semana Santa, festas juninas - ocupam quase todo o calendário. Além disso, ao deslocar-se o foco para o 
plano da família e, consequentemente, para o espaço interno das casas, na família urbana multiplicam-se os rituais de passagem - aniversários, formatura, casa nova, vitória do time - enquanto a família que vive na área rural privilegia outras cerimônias batizado, matrimônio, funeral - cujo caráter se apresenta claramente diferenciado. Neste sentido, o autor conclui:

[...] é como se no mundo da cidade a festa oscilasse entre um máximo de sentido do universal, como no Natal, no Ano Novo, e, em contrapartida, um máximo de afirmação simbólica do valor da individualidade, como no aniversário. Enquanto no campo, valem mais as cerimônias de reconhecimento de um nós local, como na festa dos santos padroeiros, e de associação da biografia individual ao ritmo e ao sentido da vida comunitária, como no batizado, no casamento e no velório (BRANDÃO, 1989, p.8).

A partir da análise de Brandão, busco iluminar as transformações que irão marcar definitivamente a maneira como Salvador atualmente trata suas manifestações culturais, com ênfase toda especial para aquelas que compõem o ciclo de festas populares da Bahia, a partir da década de cinquenta.

A cultura da festa e todo o contexto subjetivo e simbólico são produzidos nos bairros, pedaços, territórios e nas urbes negras do país. Oliveira (2016) e Junior (2019) destacam os valores culturais ancestrais dos espaços urbano e rural de organizações sociais e culturais que atuam no chão das cidades, produzindo e reproduzindo todo um caldo histórico, social e político que reforçam a luta contra as desigualdades e o racismo. A cultura é um dos meios para enfrentar a segregação e o racismo nas urbes do país, principalmente na cidade negra de Salvador.

O costume de realização de festas continua presente entre os baianos, no entanto à medida que se atualiza, muitas mudanças podem ser notadas. Entre o conjunto de mudanças que as festas sofrem está o que caracteriza o deslocamento, seja ele espacial, seja ele em relação à sua constituição organizativa. No interior desta última, encontra-se o deslocamento da responsabilidade pela organização e realização da festa.

Não faz muito tempo, a organização das festas populares cabia a um grupo de pessoas pertencentes à comunidade local. Fossem esses grupos constituídos por irmandades, grêmios ou mesmo pelo conjunto dos moradores, a escolha do responsável, ou melhor, do coordenador das atividades era feita entre seus membros ao final dos festejos em determinado ano para assegurar, no ano seguinte, ao indicado exercer a função. A este caberia prover as condições necessárias para que tudo estivesse em 
ordem no grande dia, como buscar doações, o comprometimento de pessoas influentes, pedir esmolas, promover feiras e tudo o mais que pudesse gerar os recursos condizentes com a importância da festa.

Progressivamente, essa prática foi sendo substituída, os motivos foram vários, desde o interesse do poder público por conta do peso político em função da geração de divisas e da promoção pessoal que tal evento lhes poderia facultar, até o interesse econômico que certas manifestações começavam a despertar. Olhando hoje para o tipo de produção dispensada a algumas festas do calendário baiano, tem-se a impressão que aquele modelo de organização ficou tão longe que praticamente a memória já não consegue alcançar.

As relações pessoais de antigamente dão lugar à impessoalidade dos memorandos, projetos, orçamentos, custos, despesas, funcionários e toda uma infraestrutura que assume o lugar do grupo encarregado de garantir a realização da festa que atualmente é gerida por empresas. São outros tempos. Salvador apresenta esse corte, o calendário de festejos populares da Bahia passa a ser promovido pelo governo e não mais pelo povo, que agora cumpre apenas o papel de ator na produção, de consumidor do espetáculo. Cabe às empresas que se encarregam das festas distribuir os copinhos de água, disponibilizar os fogos, contratar bandas de música, palanques, sonorização, etc. O investimento gera divisas para a cidade e prestígio aos seus gestores, por isso mesmo, nada pode dar errado. Como deve haver uma estrutura profissional para atender às exigências do público que está sendo esperado, as características da modernidade marcam as festas de largo de Salvador. É claro que elementos da tradição também estão presentes, mas imbricados com o novo.

Nas festas que a comunidade organiza, existem comissões de organização, sejam elas filiadas à igreja, às associações ou mesmo ao grupamento de alguns moradores da comunidade. Essas comissões desempenham o seu papel pelo menos nas manifestações de menor vulto, ou naquelas entre as quais tradicionalmente a própria comunidade assume o compromisso de realização da festa, especialmente devido à fé. No ciclo festivo de Salvador, provavelmente só a festa da Lavagem do Bonfim e o Carnaval, pela dimensão que assumiram, deixaram de ser organizados pelo pequeno grupo da comunidade local. Na realidade, o que ocorreu com essas festas é que elas se tornaram por demais universais, no sentido descrito por Brandão, e, portanto, a organização local constituiu-se limitada para dar conta dessa dimensão. Assim, tanto o poder público 
quanto a iniciativa privada tornaram-se indispensáveis na sua produção e patrocínio. Elas perdem o caráter local de atendimento ao devoto e ao romeiro para transformaremse em globais, ao constituírem-se na referência universal da manifestação que compõe o Ciclo de Festas Populares da Bahia.

Mas, ao se olhar para a festa da Boa Viagem - do Senhor Bom Jesus dos Navegantes -, festa que está inserida no contexto da passagem de ano, não se pode perder de vista que lá está a figura da comunidade, comprometida com a tradição local, atua junto à paróquia para organizar e realizar a festa, levando em conta traços que ela historicamente construiu. A festa mantém-se apesar de todas as transformações que levaram, por exemplo, o governo a criar e patrocinar, juntamente com a iniciativa privada, os megaeventos no outro lado da cidade. Para boa parte dos baianos de Salvador, a tradição de participar da procissão marítima, concentrar-se à margem da Baía de Todos os Santos para vê-la passar, ou mesmo aguardá-la no seu local de saída e/ou de chegada para homenagear o santo, não pode ser substituída por algum megaevento de projeção universal, criado tão-somente para atender ao mercado de caráter turístico-festivo do verão. Sob certos aspectos, isto leva a pensar que a festa baiana, por contiguidade, talvez esteja mais próxima do entendimento mostrado por Brandão (1989).

Quando digo que a festa de Bom Jesus dos navegantes continua preservando preceitos do tempo de sua criação, não quero com isso dizer que não houve transformações. Diria que os tempos são outros e aquelas embarcações foram paulatinamente substituídas cedendo lugar a outras novas. A própria Galeota, embarcação secular, encarregada de transportar a imagem do Bom Jesus, não participou do cortejo em 2019 ${ }^{3}$. Este movimento possibilitou a entrada de outro elemento no contexto da festa. Mais caras e mais sofisticadas, as embarcações que hoje acompanham o cortejo levam, na sua maioria, indivíduos que podem pagar e desfrutar das condições de conforto oferecidas por elas. Isto não significa que as embarcações de trabalho e de menor monta estejam fora da procissão marítima, o que ocorre é que elas passaram a representar, no decorrer do tempo, uma parcela menor entre as que participam do cortejo. São iates, veleiros, lanchas de todo o tamanho, jet sky e outros modelos. Os saveiros já não são vistos e as pequenas embarcações de pesca são minoria. Portanto,

\footnotetext{
${ }^{3}$ Houve um problema na estrutura, não corrigido em tempo hábil, que a impediu de participar do cortejo. Em 2020 a situação foi resolvida e a "Gratidão do Povo", nome que lhe é atribuído, voltou a navegar.
} 
embora a procissão venha crescendo em número de embarcações, o povo que sempre manteve a festa mudou de lado, vê sua tradição passar, mas esta não se encontra mais sob seu controle. Um detalhe é determinante no cortejo, tanto nas embarcações que o acompanham quanto no cais ou na praia onde acontecem o embarque e o desembarque do santo homenageado, lá está quem se colocou a serviço da manutenção da tradição: o povo.

Aquele que faz promessa, aquele que cumpre obrigação, aquele que recebe uma graça, enfim, aquele que crê na força do protetor. Nada indica, no entanto, que não deva estar ali quem apenas olha, com curiosidade ou ceticismo, com interesse promocional ou apenas pelo divertimento, pelo apelo turístico ou pelo simples fato de auferir lucro. O contexto da manifestação admite todos esses elementos e não conflita com eles, ao contrário convive, porque nessa aparente contradição talvez resida a manutenção de sua sobrevivência. Portanto, se o turista, o empresário, o incauto cidadão vem em busca de lazer, lucro e prazer, claro contribuem, cada um à sua maneira, para que a festa exista, seja vista e se mantenha.

No contexto dessas festas, vi mulheres vestidas com seus trajes de santo ricamente decorados, mas também vi outras tantas com suas vestes muito simples aquela roupa do dia-a-dia - ocupando um espaço naquele ambiente de festa. O colorido do conjunto por si só já indicava o dia de festa. Havia tantas outras pessoas em trajes de praia, em roupas leves expressando a predisposição para o lazer; também havia em número considerável pessoas com roupas pouco convencionais para o local, isto indicava que seus usuários eram estranhos ao lugar, turistas provavelmente. A diversidade de rostos e de expressões dava o tom peculiar a essas manifestações.

Como mostra Brandão, a partir dos depoimentos que chegam do século XVI ao século XIX, isto é, desde os relatos da visita feita por Jean de Lery ${ }^{4}$, duas coisas sempre espantaram a todos os viajantes europeus não-ibéricos que, por algum motivo, vieram conviver conosco a aventura do Brasil:

\footnotetext{
${ }^{4} \mathrm{O}$ francês Jean de Lery chega ao Brasil pelos anos 600, nos começos da fase de colonização do litoral brasileiro. Ele descreve com delicioso espanto uma festa de São Gonçalo realizada nada menos que dentro de uma igreja de Salvador. E o que irá surpreender esse protestante calvinista? Pois ali estão, “[...] de mãos dadas: sacerdotes, freiras, 'homens-de-bem' e o populacho da cidade'. Em segundo lugar, o que eles fazem juntos e quase sem diferenças, pois dentro da igreja e diante do altar cantam ao som de bizarros instrumentos e dançam, irreverentes e quase sensuais, em louvor do santo casamenteiro. Abraçados, ora aos pares, ora em rodas de dançantes, ei-los que celebram com dança um rito de fé.” ( BRANDÃO, 1989, p.14).
} 
Primeira: havia sempre festas, todo o tempo, por toda a parte e por todos os motivos. Segunda: ao contrário do que começou a ocorrer na Europa após a Reforma Protestante e Contra-Reforma, as cerimônias religiosas da Igreja no Brasil eram desbragadamente festivas e misturavam a tudo e a todos, de uma maneira impensável na França ou na América do Norte (BRANDÃO, 1989, p.14).

Parece o traço festivo que o baiano incorporou com primazia, a ponto de se valer da festa para comemorar o sagrado. Talvez seja porque:

A festa quer lembrar. Ela quer ser memória do que os homens teimam em esquecer - e não devem - fora dela. Séria e necessária, a festa apenas quer brincar com os sentidos, o sentido e o sentimento. E não existe nada de mais gratuito e urgentemente humano do que exatamente isto (BRANDÃO, 1989, p.17).

Dessa forma, a festa une o passado ao presente, mais precisamente, à medida que ela quer lembrar como diz Brandão, pois lembrança possui o seguinte movimento: sai do presente vai ao passado, volta ao presente. Nesta dinâmica, tem-se o encontro de elementos da tradição com a modernidade.

A característica provinciana que Salvador tinha até meados do século XX, mas que progressivamente começou a perder, irá determinar a forma de suas festas de caráter popular, especificamente aquelas que envolvem o ciclo de verão, pelas décadas seguintes. Tal fato deve-se, principalmente, à mudança de olhar em relação à cidade: modernização, turismo, deslocamento das classes abastadas da região central e, em consequência, a proletarização a marginalização do centro antigo e a crescente universalização das manifestações festivas foram alguns dos motivos para esta transformação. Logo as manifestações que sobreviveram a esse processo e outras que foram por ele possibilitadas, também ajudaram a construir a aura de modernidade que hoje a cidade assumiu.

A Festa do Bonfim é a que melhor encarna o interesse do poder público por uma manifestação de caráter popular com a intenção de promovê-la turisticamente. Nela, além dos investimentos anualmente realizados para prover a infra-estrutura da lavagem, são feitos outros tantos para a manutenção e preservação do templo. Tanto a cerimônia de abertura, isto é, de saída, quanto à de chegada do cortejo contam sempre com a presença das maiores autoridades políticas e militares do Estado. Tal empreendimento remonta aos anos cinquenta, quando foi instituído o concurso para estimular a 
participação das baianas, ricamente trajadas, cuja premiação agraciava as melhores com troféus e medalhas. Data também desse período o início da participação do poder público na promoção e financiamento dessas manifestações, como dito anteriormente.

Todo esse empenho tinha o propósito de tornar aquela manifestação visualmente mais bonita e, com isso, atrair o interesse do turista. Vale lembrar que, mesmo participando dos tais concursos, evidentemente muito atrativos, as mulheres que ali estavam acompanhando o cortejo, na sua maioria, provavelmente, o faziam pelo compromisso de fé. $\mathrm{O}$ fato de aceitarem o apadrinhamento e conseqüente participação no concurso é que, muitas vezes, rendia-lhes financiamento para aquisição dos respectivos trajes. Entre as autoridades que assumiram a condição de padrinhos dessas mulheres estavam: o Comandante do Distrito Naval, o Comandante da Polícia Militar, o Prefeito e até o Governador do Estado. Eles assumiam, durante o exercício de seus mandatos, esta condição no dia de realização da festa; a disputa pela condição da baiana mais bem vestida, mais bem caracterizada, na realidade dignificava o poder, a riqueza do padrinho; o poder estava oculto na roupa da baiana.

Algumas mulheres, entre elas uma de minhas entrevistadas, relataram que sua participação na Lavagem sempre constituiu uma obrigação para com o orixá, no entanto, segundo ela mesma chegou afirmar, sentia-se extremamente envaidecida pelo fato de ser assumida como afilhada de um político famoso do Estado e, ainda, o fato de mais tarde ter-se invertido a posição, isto é, ter-se transformado em madrinha do respectivo político durante a realização da tal manifestação. Este fato reflete uma pequena mudança na estrutura da programação: o concurso da baiana mais bem trajada deixou de existir, mas a procura da fama, bem como a busca de aproximação com políticos e pessoas socialmente influentes subsiste, e esta relação mais próxima pode, por exemplo, render participação em eventos especiais, melhorias para as localidades onde estas mulheres residem, ou mesmo dar visibilidade aos seus terreiros e a elas próprias enquanto sacerdotisas do Candomblé.

Logo a festa possui, para além da fé, a capacidade de transformar-se também em uma grande vitrine de um concurso no qual as vencedoras são aquelas que conseguem estar entre as escolhidas e até financiadas por essas pessoas. Não quero com isso dar a entender que essas mulheres são movidas só por este interesse, na realidade, trata-se de uma relação de troca. E, neste sentido, deve-se concordar com Brandão quando diz: 
Eis um sistema inicial de trocas entre pessoas que configura a própria essência da festa popular no Brasil. Porque cheia de falas e gestos de devoção, ruptura e alegria, ela afinal não é mais do que uma sequência cerimonialmente obrigatória de atos codificados de dar, receber, retribuir, obedecer e cumprir. Troca-se o trabalho por honrarias, bens de consumo por bênçãos, danças por olhares cativos, o investimento do esforço pelo reconhecimento do poder, a fidelidade da devoção pela esperança de benção celestial. Obedece-se ao mestre, ao festeiro, ao padre, ao chefe da torcida, ao maestro da banda. Cumprem-se promessas, votos feitos (BRANDÃO, 1989, p.11).

Olhar, hoje, para as fotos recentes nas quais está registrado o banho de água de cheiro (água lustral) derramada dos cântaros das baianas sobre a cabeça de autoridades e políticos que vão à festa, é como retornar no tempo. Tempo no qual um fato inusitado desta natureza poderia soar aparentemente desrespeitoso, entretanto o fato ocorreu. No lugar do desrespeito, apesar da preocupação posterior de sua protagonista, a nova situação criada se repete anualmente. Além disso, ela continuou a banhar todos os anos em que esteve presente alguma autoridade. Tal fato transformou-se em uma das lembranças mais importantes, para ela, enquanto participante da festa.

Como disse em depoimento para esta pesquisa, a aflição diante de sua condição naquele momento a fez lançar mão do único dispositivo que lhe restava: clamar pela providência divina para que fizesse algo que a tornasse vista, reconhecida e, portanto, passível de ser ouvida. Jogar sobre a cabeça do então prefeito de Salvador todo o conteúdo do seu cântaro, preparado para a lavagem da igreja como ela própria descreveu, produziu esse efeito; o gesto de que fora protagonista adiante lhe abriu a possibilidade de ser ouvida e respeitada.

E mais, corajosamente foi à procura do chefe do executivo municipal, recebida por ele, sentiu-se aliviada ao ouvir que sua atitude passada lhe fizera bem. A partir deste momento, a ordem na relação entre baianas e autoridades, na Lavagem, transformara-se: deixou de ser, dali em diante, o representante da sociedade local, o padrinho que sempre foi, e passa a ser tão-somente o afilhado daquela mulher, assim como tantos outros depois o foram.

O espírito de fé e religiosidade das mulheres, aliado à força pela necessidade de sobreviverem, sobrepujou o poder dos políticos e dos influentes da cidade, pelo menos, durante a Lavagem. Pelo banho que lavou aquela cabeça, inventou-se a tradição cujo significado lembra o renascimento para uma nova vida, tanto no Cristianismo como também no Candomblé. Diria mesmo que este renascimento deve vir aliado com axé, com poder. 
Como na Lavagem do Bonfim, também nas cerimônias de saída do Bloco Ilê Aiyê, o chefe do executivo municipal se faz representar. Toma parte no ritual que abre os caminhos, tanto para o desfile do bloco quanto para todos os participantes daquela ação; o prefeito e outros membros de vários segmentos da sociedade soltam pombos brancos em oferenda ao orixá e em clamor à paz no transcurso da festa e da vida das pessoas. Ele participa, mas quem determina (preside) a condução daquele ato é a mulher que orienta espiritualmente a condução do bloco. Cabe a ela ou a sua sucessora esta função cujo exercício se dá desde o primeiro dia em que o bloco saiu às ruas. Do mesmo modo, coube a essa mesma mulher, em certo momento histórico ${ }^{5}$, assumir a condição de guardiã das chaves da cidade, desta feita em cerimônia presidida pelo prefeito que oficialmente lhe passou às mãos tal responsabilidade. O processo de escolha, o convite $\mathrm{e}$ a consumação do ato refletiram, mais uma vez, o respeito para com a pessoa, mas sobretudo para com o que ela representa no contexto da cidade.

Em contraste com esses exemplos, existem tantas outras festas tradicionais do calendário que nem sequer recebem a visita de políticos ou pessoas influentes. Quando muito, essas manifestações sobrevivem das solicitações de ajuda feitas pelos organizadores ao longo do ano, sendo algumas encaminhadas aos governos, seja da esfera municipal, seja da esfera estadual. Se aceitas, a ajuda fica resumida à colocação de iluminação pública na área onde a manifestação se realiza e o apoio do setor de trânsito no momento da realização das procissões ou cortejos. Neste caso, cumpre ao realizador - comunidade e igreja - a obrigação de solicitá-la sob o pretexto de não tumultuar o trânsito nas artérias por onde o cortejo ou procissão irá se deslocar.

Exemplo ainda existente dessa situação é a festa de Santa Luzia, cuja igreja Matriz do Pilar - em dado momento encontrou-se quase destruída por conta do abandono a que foi submetida por parte do poder público. As precárias condições em que durante muito tempo a paroquia se encontrou a impossibilitaram de receber adequadamente os fiéis que para lá se deslocavam. As missas eram realizadas no adro da igreja porque o teto ameaçava desabar; localizada numa área antiga da cidade, completamente degradada e habitada por pessoas de poucas condições financeiras e outras tantas marginalizadas pelas próprias condições de sobrevivência, o espaço ainda desperta pouco interesse como área de roteiro turístico, embora o templo seja um tesouro do século XVIII/XIX fixado numa área de comércio outrora expressivo. Mas é

\footnotetext{
5 2003, o ano em que a baiana foi tema do carnaval.
} 
apenas o templo, não há outros imóveis que justifiquem uma intervenção mais intensa, mais lucrativa, logo fica à mercê da própria sorte. Neste caso especifico, são apenas os fiéis e os habitantes do lugar que garantem a realização da festa.

Se realizarmos um recuo no tempo e nos situarmos no intervalo correspondente ao período anterior ao trabalho de recuperação urbana do Sítio Histórico do Pelourinho, será possível notar, por exemplo, que a festa de Santa Bárbara ali realizada padecia da mesma carência de apoio e se mantinha exclusivamente pela força e a fé de seus fieis, tanto os católicos quanto os adeptos do Candomblé. Entretanto, com a recuperação do Centro Histórico, a festa também reviveu e assumiu contorno de uma das maiores manifestações do calendário de festas populares da Bahia. Neste sentido, é possível acreditar que as transformações urbanas, os deslocamentos de interesse fazem com que as festas baianas sejam diretamente atingidas.

Um fato concreto reforça essa afirmação e vincula-se ao movimento de duas manifestações festivas da cidade: uma pelo desaparecimento da manifestação em virtude da não adaptação à transformação do locus onde se realizava - a festa passou a conflitar com os interesses da população que se instalou no lugar; na outra, ao contrário, a manifestação integrou-se ao movimento da população do lugar e, portanto, cresceu, ganhando com isso notoriedade. São elas, respectivamente, de um lado a Festa da Pituba, cujo bairro assume atualmente características de área socialmente privilegiada; e de outro a cerimônia de saída do Bloco Afro Ilê Aiyê na noite do sábado de carnaval no Bairro da Liberdade.

Ambas refletem o extremo que caracteriza as relações entre a manifestação festiva e a população do lugar. Se, por um lado, a população resiste às manifestações daí decorrentes e as festas tendem a subsistir, manter-se e atualizar-se para não desaparecer, por outro, se a tradição entra em choque com os interesses da população, o resultado é a instauração do conflito. Como consequência, a manifestação tende a progressivamente desaparecer ou pode, ao contrário, pela força que a manifestação possui no contexto da cidade, muitas vezes sobrepujar a hostilidade da população obrigando-a ao afastamento do local, mesmo em caráter temporário, isto é, durante a realização da manifestação ou em definitivo, procurando outros lugares onde se fixar. É a resistência.

Nos tempos atuais, foi possível verificar, a partir do noticiário dos jornais, o desenrolar de duas situações parecidas: a primeira envolvendo a população do Bairro da Barra quanto à transferência de parte dos desfiles de carnaval para aquela área, a força 
da festividade sobrepujou o descontentamento da população local. O resultado obvio foi: parte da população tradicional do bairro migrou para outras localidades longe do movimento da festa e outra parte se ausenta do bairro nos períodos em que a festa acontece. Faz algum tempo que esta migração vem constituindo meio de geração de renda, as residências antes vazias agora são alugadas para quem deseja participar da festa.

A outra situação se deu com a criação do "Candeal Gueto Square", centro de cultura popular e espetáculos criado por um músico famoso da cidade numa área anteriormente habitada por uma população de baixa renda. Neste caso, dado que a área se transformou, toda uma população socialmente privilegiada para lá se deslocou. No entanto, fato curioso ocorreu, pois, se houve uma transformação espacial com a urbanização acelerada, a nova população exigente, intolerante com tais manifestações culturais conseguiu, por força de ação pública, proibir toda e qualquer manifestação que se vinculasse aos espetáculos realizados no dito Centro. Mais uma vez a história se repete.

Assim, as festas de largo em Salvador que unem brancos e negros, ricos e pobres, estrangeiros e brasileiros, podem ser vistas sob a ótica de suspensão do cotidiano, pois no dia-a-dia as divisões são visíveis.

\section{REFERÊNCIAS BIBLIOGRÁFICAS}

A COLINA Sagrada está pronta para a grande festa de hoje. A Tarde, Salvador, p.3, 17 jan. 1980.

A FESTA da "lavagem"suplantou a expectativa e levou grande multidão à Colina Sagrada. $A$ Tarde, Salvador, p.3, 12 jan.1962.

A LAVAGEM da Igreja movimentou a Pituba. A Tarde, Salvador, p.3, 4 fev.1983.

AMADO, Jorge. Bahia de Todos os Santos: guia de ruas e mistérios. Rio de Janeiro: Record, 2000 .

ANDRADE, Maria José Souza de. A mão de obra escrava em Salvador, 1811/1860. São Paulo: Corrupio; Brasília-DF: CNPq, 1988.

AZEVEDO, Thales de. Povoamento da Cidade do Salvador. 2. ed. rev. São Paulo: Nacional, 1950. (Biblioteca Pedagógica Brasileira, Série V, Brasiliana, v. 281).

BAHIA.Centro de Estatística e Informações (CEI). Companhia de Desenvolvimento da 
Região Metropolitana de Salvador (CONDER). Informações básicas dos municípios baianos: Região Metropolitana de Salvador. Salvador, 1994.

BAIANOS e "baianas" lavam hoje a Igreja do Bonfim. A Tarde, Salvador, p.3, 16 jan.1986.

BAIANOS renovam a tradição de dois séculos no Bonfim. A Tarde, Salvador, p.3, 17 jan.1986.

BANDAS de percussão e Sopro animam o cortejo da Lavagem. A Tarde, Salvador, p.3, 15 jan.1998.

BARRETO, Luciana. Personagens emblemáticos expõem alma da cidade. Correio da Bahia, Salvador, 29 mar.2004. Aqui Salvador, p.6.

BARTH, Fredrik. Grupos étnicos e suas fronteiras In: POUTIGNAT, Philippe e STREIFFFENART, Jocelyne. Teorias da Etnicidade: seguido de Grupos Étnicos e Suas Fronteiras de Fredrik Barth. Tradução de Elcio Fernandes; São Paulo: UNESP,2000. p.185227.

BARTHES, Roland. A câmara clara: nota sobre a fotografia. Tradução de Júlio Castañon Guimarães. Rio de Janeiro: Nova Fronteira, 1984.

BASTIDE, Roger. O Candomblé da Bahia: rito nagô. Tradução de Maria Isaura Pereira Queiroz. São Paulo: Campanhia das Letras, 2001.

BERNARDO, Terezinha. Mulheres, negras e mães: memórias de Olga de Alaketo. São Paulo: EDUC; Rio de Janeiro: Pallas, 2003.

BICHARA, Mônica. Receita gerada pelo turismo deve crescer 8\%. Correio da Bahia, Salvador, 2 jan.2004. Correio Negócios, p. 4-5.

BINA, Gabriel Gonzaga. O atabaque na igreja: a caminho da inculturação litúrgica em meios afro-brasileiros. Mogi Das Cruzes, São Paulo: Brasil, 2002.

BOCHICCHIO, Regina. A caminho do adro sagrado. A Tarde, Salvador, p.3, 16 jan.2004.

BONFIM, José. Sincretismo, momento de fé e união. A Tarde, Salvador, p.4, 05 dez.2003.

BORNHEIM, Gerd et al. Cultura brasileira: tradição contradição. Rio de Janeiro: Jorge Zahar, 1987.

190

BOSI, Alfredo. Cultura como tradição In: BORNHEIM, Gerd et al. Cultura brasileira: tradição contradição. Rio de Janeiro: Jorge Zahar, 1987. p. 31-58.

BRANDÃO, Carlos Rodrigues. A cultura na rua. Campinas, São Paulo: Papirus, 1989.

CADERNO de Educação do Ilê Aiyê: a força das raízes. Salvador, 1997. v. 4.

CADERNO de Educação do Ilê Aiyê: Guiné Conacry. Salvador, 1998. v. 6.

CADERNO de Educação do Ilê Aiyê: organizações de resistência negra. Salvador, 1995. v. 1.

CAILLOIS, Roger. Paisagens, sábios e selvagens. Porto, Portugal: Bloco Gráfico, 1993. 
CARNEIRO, Edison. A Cidade do Salvador, 1549: uma reconstrução histórica; A conquista da Amazônia. 2. ed. Rio de Janeiro: Civilização Brasileira; Brasília: INL, 1980.

CARNEIRO, Edison. Candomblés da Bahia. 5. ed. Rio de Janeiro: Civilização Brasileira; Brasília, DF: INL, 1977.

CASTRO, Yeda Pessoa de. Falares africanos na Bahia: um vocabulário afro-brasileiro. Rio de Janeiro: Academia Brasileira de Letras; Topbooks, 2001.

CASTRO, José. Chegou a vez de Itapuã: festa de largo - uma das últimas farras précarnavalescas, a lavagem do "principado" é amanhã. A Tarde, Salvador, p.3, 19 fev.2003.

CELESTINO, Samuel. A inclusão e a exclusão do carnaval. A Tarde, Salvador, 3 mar.2003, Caderno 1, p.15.

CONSORTE, Josildeth Gomes. Em torno de um manifesto de ialorixás baianas contra o sincretismo. In: CAROSO, Carlos; BARCELAR, Jéferson (Org.). Faces da tradição afrobrasileira: religiosidade, sincretismo, anti-sincretismo, reafricanização, práticas terapêuticas, etnobotânica e comida. Rio de Janeiro: Pallas; Salvador, Ba: CEAO, 1999. p.71-91.

CORTEJO parte da Conceição para lavar Bonfim dos maus espíritos. A Tarde, Salvador, p.3, 11 jan.1968.

CRUZ, Gutemberg. Gente da Bahia. Salvador: P\&A, 1997.

CRUZ, Gutemberg.Gente da Bahia II. Salvador: P\&A, 1998.

DAMATTA, Roberto. A casa e a rua: espaço, cidadania, mulher e morte no Brasil. São Paulo: Brasiliense, 1985.

DUBOIS, Philipe. O ato fotográfico. Tradução de Marina Appenzeller. Campinas, São Paulo: Papirus, 1993.

DURAND, Gilbert. $O$ imaginário: ensaio acerca das ciências e da filosofia da imagem. Tradução de Renée Eve Levié. Rio de Janeiro: DIFEL, 1998.

ELIADE, Mircea. Imagens e símbolos: ensaios sobre o simbolismo mágico-religioso. Tradução de Sonia Cristina Tamer. São Paulo: Martins Fontes, 1991.

ELIADE, Mircea. O sagrado e o profano. Tradução de Rogério Fernandes. São Paulo: Martins Fontes, 1992.

FELDMAM-BIANCO, Bela; LEITE, Míriam L. Moreira (Org.) Desafios da Imagem: fotografia, iconografia e vídeo nas ciências sociais. Campinas, São Paulo: Papirus, 1998.

FESTA do Bonfim. A Tarde, Salvador, p.1, 17 jan.1980.

"FILHOS DE GANDHY" magnetiza foliões. A Tarde, Salvador, p.3, 12 fev.1986.

FOGOS de artifício acordam a Pituba. A Tarde, Salvador, p.3, 17 fev.1987.

FONSECA, Raul. Políticos fazem a festa na Lavagem do Bonfim. A Tarde, Salvador, p.10, 16 jan.1998. 
GEERTZ, Clifford. A interpretação das culturas. Tradução de Fanny Wrobel. Rio de Janeiro: Zahar, 1978.

GEERTZ, Clifford. O saber local. Tradução de Vera Mello Joscelyne. Petrópolis: Vozes, 1997.

GÓES, José Araújo. Procissão de fé: em agradecimento à graça alcançada fiéis prestaram homenagem à santa. A Tarde, Salvador, 14 dez.2002. Caderno 1, p.2.

GOMES, Heloisa Toller. As marcas da escravidão: o negro e o discurso oitocentista no Brasil e nos Estados Unidos. Rio de Janeiro: UFRJ - EDUERJ, 1994.

GURAN, Milton. Agudás: os "brasileiros” do Benim. Rio de Janeiro: Nova Fronteira, 2000.

HALBWACHS, Maurice. Memória coletiva. São Paulo: Vértice, 1990.

HOBSBAWN, Eric; RANGER, Terence. A invenção das tradições. Tradução de Celina Cardim Cavalcante. Rio de Janeiro: Paz e Terra, 1997.

JACOB, Adriana. E essa tal baianidade. Correio da Bahia, Salvador, 29 mar.2004. Aqui Salvador, p.3.

JUNIOR, Henrique Cunha. Bairros Negros: a foruma urbana das populações negras no Brasil. Revista da Associação Brasileira de Pesquisadores Negros (ABPN), v. 11. Número especial, p.65-86, maio 2019. ISSN 2177-2770. Disponível em: 〈https://abpnrevista.org.br/index.php/site/article/view/683>. Acesso em: 10 abril. 2020 LAVAGEM anima a festa da Pituba. A Tarde, Salvador, p.3, 3 fev.1983.

LAVAGEM da Igreja da Pituba perde a animação. A Tarde, Salvador, p.3, 20 fev.1987.

LAVAGEM do Bonfim. A Tarde, Salvador, p.3, 14 jan.1965.

LAVAGEM do Bonfim será amanhã. A Tarde, Salvador, p.3, 14 jan.1987.

LAVAGEM do Bonfim: uma história de proibições, conflitos e muita fé. A Tarde, Salvador, 15 jan.1987. Caderno 2, p.1.

LAVAGEM mais tranqüila sem trios elétricos. A Tarde, Salvador, p.1, 16 jan.1998.

LEAL, Geraldo da Costa. Perfis urbanos da Bahia: os bondes, a demolição da Sé, o futebol e os galegos. Salvador: Gráfica Santa Helena, 2002.

LODY. Raul. O povo de santo: religião, história e cultura dos orixás, voduns, inquices e caboclos. Rio de Janeiro: Pallas, 1995.

MAGNANI, José Guilherme Cantor. Festa no pedaço: cultura popular e lazer na cidade. 2. ed. São Paulo: Hucitec; UNESP, 1998.

MATTOSO, Katia M. de Queiroz. Bahia, Século XIX: uma província no Império.Rio de Janeiro: Nova Fronteira,1992.

MAUSS, Marcel. Esboço de uma teoria geral da magia. Tradução de José Francisco Espadeiro Martins: Lisboa: Edições 70, 2000. 
MEMÓRIA do Bonfim. A Tarde, Salvador, p.1, 16 jan.2003.

MISÉRIA ameaça lares de 300 carroceiros da Bahia. A Tarde, Salvador, p.3, 18 jan.1968.

MISTURA de fé e samba na lavagem. A Tarde, Salvador, p.3, 16 jan.1987.

MORIN, Edgar. O enigma do homem. Tradução de Fernando de Castro Ferro. 2. ed. Rio de Janeiro: Zahar, 1979.

MOURA, Milton. A crise dos blocos de trio. A Tarde, Salvador, 3 mar.2003.

Caderno 1, p.11.

OLIVEIRA, Cláudia. Odô yá, minha mãe. A Tarde, Salvador, 2 fev.2003. Caderno 1, p.7.

OLIVEIRA, Flávio. Lembranças do Bonfim. A Tarde, Salvador, p.7, 16 jan.2003.

OLIVEIRA, Reinaldo José de. Territorialidade Negra e Segregação Racial em São Paulo: a luta por cidadania no século XX. São Paulo, Editora Alameda, 2016.

O MONDO: Boletim informativo. Salvador, n.19, fev. 2003.

ORTIZ, Renato. Cultura brasileira e identidade. 5. ed. São Paulo: Brasiliense, 1994.

OS CLARINS na Pituba. A Tarde, Salvador, p.3, 20 jan.1978.

POLLAK, Michel. Memória e identidade social. Estudos Históricos, Rio de Janeiro, v.5, n. 10, p.200-212, 1992.

POLLAK, Michel. Memória, esquecimento, silêncio. Estudos Históricos, Rio de Janeiro, vol. 2, n. 3, p.3-15, 1989.

POUTIGNAT, Philippe; STREIFF-FENART, Jocelyne. Teorias da Etnicidade: seguido de Grupos étnicos e suas fronteiras de Fredrik Barth. Tradução de Elcio Fernandes. São Paulo: UNESP, 2000.

PÓVOAS, Ruy do Carmo. A linguagem do candomblé: níveis sociolingüísticos de integração afro-portuguesa. Prefácio de Celso Cunha. Rio de Janeiro: José Olimpio, 1989.

PRANDI, Reginaldo. Um sopro do espírito: a renovação conservadora do catolicismo carismático. 2. ed. São Paulo: Editora da Universidade de São Paulo: FAPESP, 1998.

PRANDI, Reginaldo. Mitologia dos orixás. São Paulo: Cia das Letras, 2001.

PROUST, Marcel. O tempo redescoberto. Tradução de Lúcia Miguel Pereira. 13. ed. São Paulo: Globo, 1998.

QUEIROZ, Lúcia Aquino. Turismo na Bahia: estratégias para o desenvolvimento. Salvador: Secretaria da Cultura e Turismo do Estado da Bahia, 2002.

QUERINO, Manuel. A raça africana e os seus costumes. Salvador: Praça da Sé, 1955.

QUERINO, Manuel. Costumes Africanos no Brasil. 2. ed. ampliada e comentada. Recife: Fundação Joaquim Nabuco; Massangana, 1988. 
RAMOS, Alberto Guerreiro. Introdução crítica à sociologia brasileira. Rio de Janeiro: Editora UERJ, 1995.

RAMOS, Arthur. A aculturação negra no Brasil. São Paulo: Nacional, 1942.

RAMOS, Arthur. As culturas negras: introdução à antropologia brasileira. Rio de Janeiro, Guanabara: Livraria Editora da Casa do Estudante do Brasil, 1949. v.3.

RAMOS, Arthur. O negro brasileiro. 2. ed. Recife: Fundação Joaquim Nabuco; Massangana; 1988.

RAMOS, Cleidiana. Amanhã tem festa da padroeira. A Tarde, Salvador, p.7, 7 dez.2003.

REIS, João José; SILVA, Eduardo. Negociação e conflito: a resistência negra no Brasil escravista. São Paulo: Companhia das Letras: Schwarcz, 1989.

REPETE-SE a tradição. A Tarde, Salvador, p.3, 3 fev.1962.

RIBEIRO, João Ubaldo. Viva o povo brasileiro. Rio de Janeiro: Nova Fronteira, 1984.

RICOEUR, Paul. Ideologia e utopia. Tradução de Teresa de Louro Perez. Lisboa: Edições 70, 1991.

ROCHA, Nikas; BOCHICCHIO, Regina. Festa de largo feita por gente de casa. A Tarde, Salvador, p. 4, 13 fev. 2004.

RODRIGUES, Nina. O animismo feitichista dos negros bahianos. Rio de Janeiro: Civilização Brasileira, 1935.

RODRIGUES, Nina. Os africanos no Brasil. 7. ed. São Paulo: Nacional; Brasília: Editora da Universidade de Brasília, 1988.

ROMARIA ao Bonfim, é prova de fé: festejos começam hoje e só termina segunda feira, com fanfarras, na Ribeira. A Tarde, Salvador, p.3, 13 jan.1962.

SAMAIN, Etienne. Questões heurísticas em torno do uso das imagens nas Ciências Sociais. In: FELDMAM-BIANCO, Bela; LEITE, Míriam L. Moreira (Org.). Desafios da Imagem: fotografia, iconografia e vídeo nas ciências sociais. Campinas, São Paulo: Papirus, 1998.

SANTANA, Jussilene. Contagem regressiva: trânsito e comércio se adaptam para a Lavagem do Bonfim, maior festa popular do Estado. Correio da Bahia, Salvador, 14 jan. 2004. Aqui Salvador, p.1.

SANTANA, Marise de. O legado ancestral africano na diáspora e o trabalho do docente: desafricanizando para cristianizar. 2004. 224f. Tese (Doutorado em Ciências Sociais, Antropologia): PUC- SP, São Paulo, 2004.

SANTOS, Juana Elbein dos. Os Nàgô e a morte: Pàdê, àsèsè e o CultoÉgun na Bahia. 9. ed. Traduzido pela Universidade Federal da Bahia. Petrópolis: Vozes, 1998.

SENA, Consuelo Pondé de. Do entrudo ao carnaval da Bahia. A Tarde, Salvador, 3 mar.2003. Caderno 1, p.6.

SERRA, Ordep. Rumores de festa: o sagrado e o profano na Bahia. Salvador: EDUFBA, 1999. 
SILVA, Francisco Carlos Cardoso da. Construção e (dês) construção de identidade racial em Salvador: MNU e Ilê Aiyê no combate ao racismo. 2001. 175f. Dissertação, (Mestrado em Sociologia) - Universidade Federal da Paraíba, Campina Grande, 2001.

SIQUEIRA, Maria de Lourdes. Agô Agô Lonan. Belo Horizonte: Mazza, 1998.

SODRÉ, Muniz. A verdade seduzida: por um conceito de cultura no Brasil. 2. ed. Rio de Janeiro: Francisco Alves, 1988a.

SODRÉ, Muniz. O terreiro e a cidade: a forma social negro-brasileira. Petrópolis, Rio de Janeiro: Vozes, 1988b.

SODRÉ, Muniz. Claros e Escuros: identidade, povo e mídia no Brasil. 2. ed. Petrópolis, Rio Janeiro: Vozes, 2000.

SOUSA JUNIOR, Vilson Caetano. Orixás, santos e festas. Salvador: Ed. UNEB, 2003.

TEIXEIRA, Cid. Salvador: História visual. Salvador: Correio da Bahia, 2001. 272p. il.

TEIXEIRA, Cid; Gustavo Falcón. Bahias. [Textos em português]; BARRETO, Helen Sabrina Gledhil. [versão para o inglês]. Salvador: Governo do Estado da Bahia: Corrupio, 1990.

VASCONCELOS, Levi; SOUZA, Marcone de; MUHR, Simone. Mudanças reduzem agitação da festa. A Tarde, Salvador, p.3, 16 jan.1998.

VASCONCELOS, Toni. Vôos Charters trarão estrangeiros. Correio da Bahia, Salvador, 2 jan. 2004. Correio Negócios, p.5.

VERGER, Pierre. Artigos. Salvador: Corupio, 1992.

VERGER, Pierre. Fluxo e refluxo do tráfico de escravos entre o golfo do Benin e a Bahia de Todos os Santos dos séculos XVII a XIX. Tradução de Tasso Gadizanis. 4. ed. Salvador: Corrupio, 2002.

VERGER, Pierre. Notícias da Bahia de 1850. Tradução de Maria Aparecida de Nóbrega. 2. ed. Salvador: corrupio,1999.

VERGER, Pierre. Retratos da Bahia -1946 a 1952. Salvador: Corrupio, 1980.

VERÔNICA, Silvia. Idosos enfeitam-se para manter tradição de Reis. A Tarde, Salvador, 06 jan. 2002. Caderno 1, p.4.

Recebido em: 22/09/2020

Aceito em: 30/10/2020 